\title{
Topic-Drug abuse: A study and result of Indian distress and unfullfillment of human psychological applications.
}

\author{
Dr Kapil Dev Sharma, ${ }^{2}$ Sangita Gupta, ${ }^{3}$ Shilpa Behl, ${ }^{4}$ Anita Pati Mishra \\ ${ }^{I}$ P.H.D, D.Litt. (English) Associate Professor CET IILM Greater Noida U.P \\ 2 Professor \&Dean (Student Welfare) Cet, IILM Greater Noida \\ ${ }^{3}$ H.O.D ( Applied Sciences) \& Associate Professor Cet, IILM Greater Noida \\ ${ }^{4}$ Associate Professor Cet, IILM Greater Noida
}

\begin{abstract}
The concept of drug abuse, drug-depandence, drug addiction and abstinence synderome need some clarity. Drug is a chemical substance, associated with distinct physical and psychological effects.It alters a person's normal bodily processes or functions, but this defination is too broad. In medical terms a drug is substances prescribed by a physician or manufactured expressely for the purpose of treating and previnting diseasease and ailment by its chemival nature and effect on yhe structure and functions of a living organism. In the psychological and sological context, drug is a term of habit formaing substance which directly effect upon the brain or nervous system. On the other hand any chemical substance which affect bodily function, mood, perception or consciousness, which has potential for misuse and which may be harmful to the individual or the socity. In terms of this defination the frequient use of drug is considered so dangerous and sometime even immoral and anti-social that it arouses the veriety of indegent and hostile sentiments on the part of general public.
\end{abstract}

KEY WORDS : Role of drug and its pschological effect Drug related issues and reforming psychology of drug addicts

\section{INTRODUCTION}

Puri, the holy seat of Lord jagannath and with a population of over more then two lakh, is steeped in a drug abuse culture since times immemorial because charas,bhang,opium,ghanja have enjoyad treditional importance, while the use of heroin and brown sugar begen inthe early seventies.The traditional culture of free distribuation and use of bhang during the worship of Trinath,the deity comprising brahma,Vishnu,Mahesh by one and all regardless of age and sex got transformed into drug abuse with the advent of forigners, who began flocking to Puri mainly for two reasons one food and accommaodation is cheap here and two narcotics are easily avilable.Their advent and the tendancy to sell off their possessions cameras, mobile phones,taperecorder or othersmall but expensive gadgets, brought in over the years a horde of touts, drug peddlers and middlemen who catered the tourist, special interest and stuck it rich in the process. Today puri is a drug paradise. About $30 \%$ of the adults male even females in the city are estimated to be drug addicted.Motivational factors in routine drug abuse Now what are the major causes of drug abuse? The causes may be classified under four important and visable heads

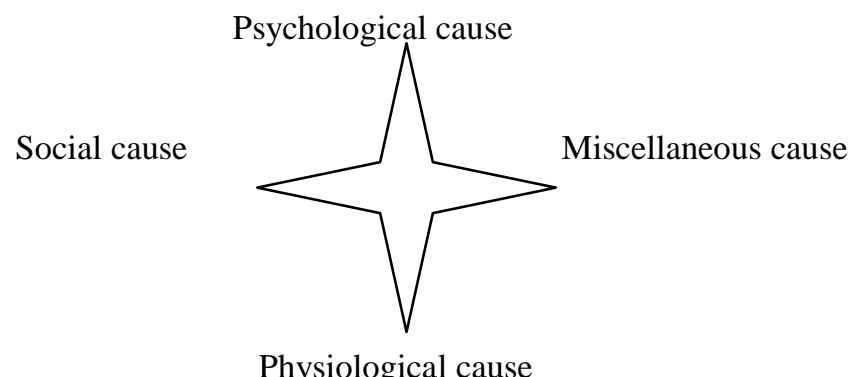

My study for this artical is moving around 5000 (thousand) university student revealed that of the 1409 students who consumed drugs $85 \%$ took drugs because of their psychological reasons, $10 \%$ becauseof social reasons and $28 \%$ because if miscellaneous reasons. The detailed analysis poiunted at that the largest number of drug using students comprised individuals who were devoted to pleasure, seeking new excitment and thrill, similarly a small number took drugs as an escape mechanism or to allevate distress.On other hand a very small number of students receiving drugs in the course of medical treatmaent for the relief of pain continued to take them long after the treatment was over. It will not be out of place here to point out that famous Lindesmith (1940-120) too has provuided a detail critique of the theory of "Psychopathic personality or psychopathic predisposition". As of 
my personal opinion drug abuse is a learnt behaviour, acquired by individual in interaction with peer, acquaintances, family member and other in actually three ways.

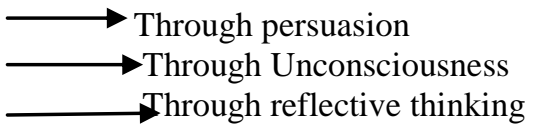

In the analysis of the soureses of getting drugs it was found few but important reasons like

1. Drugs were generally obtained from the non-medical sourses like frind,home,family members

2. Medical sourses were used more by girls then by boys

3. The non-medical source mentioned most often was Friend.

My study of students showed that the important causes of abstinence and discontinuation were:

\section{Personal $49.3 \%$}

Economics $4.1 \%$

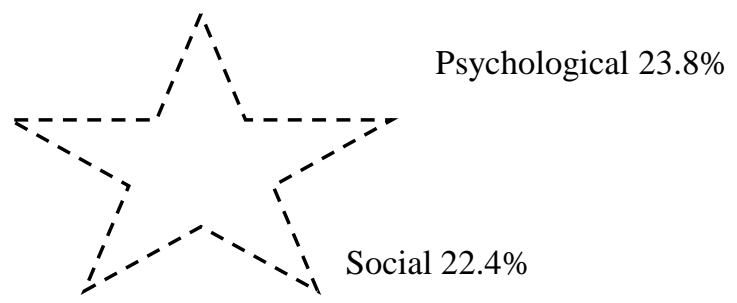

The personal causes were: Lack of interest, curiosity, pesonal dislike, hatered for the use of drugs and nonavilability of drugs.

The psychological causes: Were risk of physical and mental dengers or detorating health, risk of dependance on the drug and having had a bad experince of "Being on the trip"the social cause was that individual had either no money to purchase drugs or found drug too expensive.

Role of family and peer group in drug abuse

Family and peer group associations are the primary potent influnces upon the directions, which individual take and maintain in his life. A hypothesis in my own study of drug abuse among college and university students was that drug usages was influnced by the quality of affictonate family relationship. This term was opeartionalized on the following bases:

1. Parents take an interest in the career of their children and are conscious of their parental obligation.

2. Relations between parents of drug users between drug users and their parents and between users and their siblings are based on harmony and solidarity.

3. Parental control is neither very harsh nor very leninent so as to give an opportunity to the child for self exploration.

4. The size of family is so manageble in term of family income that no child in the family suffers from the unfulfillment of the necessities of life.

5. Parents broadly confirm to social and moral norms setting examples for their childrens to follow

6. The child exhibts a feeling of trust and security in the perants by taking them into confidence and by seeking their advice and help in facing preplaxing problems.

7. The nature of family control, the iscipline imposed by the parents over the children, even the drinking, smoking and drug taking behaviour of family members also had a bearing on the use of drugs. On the basis of above analysis it may be pointed out that the main cause of drug abuse are....

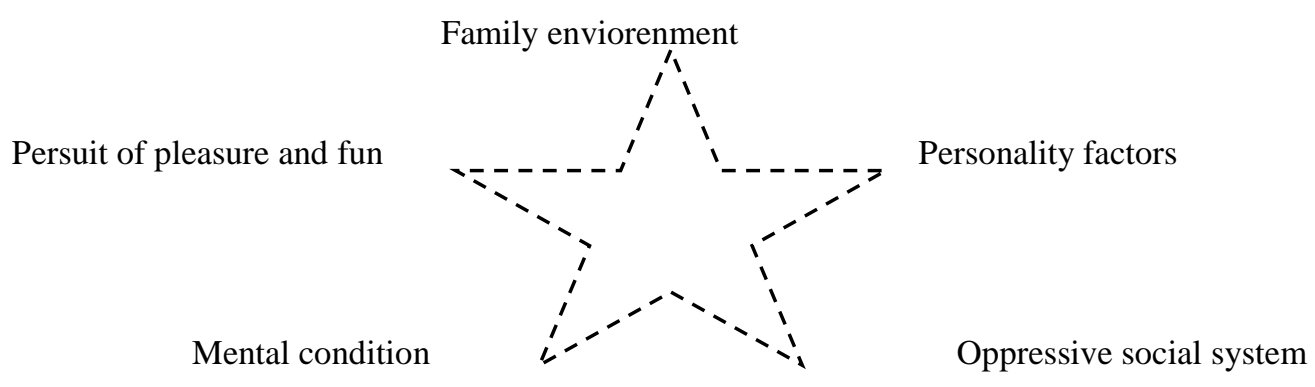

Extant and nature and drug abuse 
A survey conducted in late 1980 by the department of applied psychology of Calcutta university and sponsored by the state relief and welfare department,described calcutta a city more then eleven million people, as having the highest consontration of drug addicts in the country. It pulled the number of addicts 68,518, but source expert like Mr, Hunt believed that since drug addiction is a vicious chain and one addict introduces the habit to others and each known addict there are atleast ten unknown ones, there must be a crowd seven lakh addicts in Calcutta city toda. Calcutta may top the list but the chain is lengthening fast throughout the country. In January 1989, the union welfare ministery sponsored and study on" Assesment of drug abuse"and drug precaution services in 33 cities and tourns, excluding Calcutta. This study gave the idea of damage done by drugs. Similaly in Mumbai, the largest metro, the number of addicts according to the research stood at 1, 59,880 at the end of 1988. In amritser with the population of more then 8.2 lakh the number of addicts was estimated to be 1,589 per one lakh population. In Delhi, with a population of more then eight million the number of addicts in 1988 was estimated as 5,550.with the formula that for one known addict, there are 10 unknown addicts; the number of addicts may easily be put as 55,000. In north east hill region which lies in the proximity of the golden tringle area, $10 \%$ of the population is described as addicted to drugs like heroin, ganja, charas, bhang and phensedyle. Guwathi and imphal are described as worse. The drug addicts comprise between $10 \%$ and $30 \%$ of the population.

\section{Aberent behaviour}

Drug abuse may be percieved both as abberent behaviouer and a socual behaviour.In the formal sense, it is regarded as an evidence of individuals social maladjustment.In the lateral sense it is viewd as a widespred condition that has harmful consequences for socity. In several western countries, drug abuse was regarded as an important social problem since long but in India it is only since last one and a half decade, that it has come to be cosidered a crucial problem. India has about 10 lakh heroins (Drug) addicts alone. India drug lords monthly sale in the domestic and international market varies between 100 crore and 125 crore. Like wise the quality of illict drugs seized between 1986 and 1989 has increased over 1000\%.The use of illict drugs today is not confined to the street urchins and the lower classes more and more middle classes and upper class youth are succumbing to drugs. Inspite of this increase drug abuse in India is still considered more as an abberent behaviourthen an antisocial or a non- conforming behaviour.by this one means that the abberent personconceals his transgression from social norms opf socity. Violets norms without questioning, their legitimacy and attempt to escape the personalities of violating norms without proposing changes in them. The abberent person is believed to be out to satisfy his private interests. It wads Mr, Merton (1979) who has distinguished behaviour in two catagory.

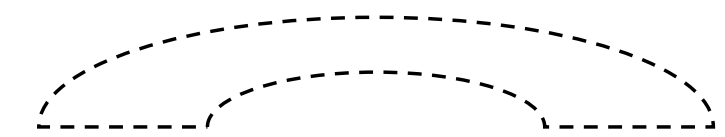

Abberent behaviour

Non-conforming behaviour

His main concern was to show the significance of various kind of normsviolation, according to him the " nonconformist" challanges the ligitimacy of the norms and he publicly rejects and advoicates the substituation of nw norms, but the abberent person neither questions the legitimacy of norms nor seek replacement of old norms with new norms. Bo wonder sociologists percieve drug abuse in India as abberent behaviour and drug users and addictsas abberent person, who unlike non-conformist are not interested in improving social conditions or benefiting menkind. There is no doubt several researches have been conductedon drug abusein India in the lasttwo decdes by medical scientists, psychiartrist and sociologist. This author conducted two studies on drug abuse among different age group students in 1976 and 1986 espically in Rajasthan, not only to analyze the problem of extended drug abuse but also to study its cause and suggest measyres for controlling it, before examining the findings of my own and other researches. We must understand a most general factor ie;

Nature and impact of abusable drug

The abusable drug may bedevidedinto six catagories:

1. Alcoholic drug- It is usedby some people normal, pleasent and sociably activity, while other take it as a spur which enables them to work. Alcohol relieves tension and lessens aggressive inhibitions. It also impairs judgement and creats confusion.

2. Sedative drugs- Relex the central nervous system, induce sleep and provinding a claming effect. Trinquilizers and barbiturates fall into this catagory. Medically these are used in high blood pressure, insomnia, epilipesy and to relexpatients before and during surgery.

3. Stimulants- These drugs activates the central nervous system and relieve tensions, treat mild depression and keep a person awake, increase alartness, contract fatigue and expressive drowisness. Themostwidely known 
stimulantes are amphetamines, caffine and cocaine. The heavierdosees of stimulants cause extreme nervousnes, headache, sweating, diarrhoea and unclear speech. The factors of stimulators are that these drugs do not produce physical depandance, though they are psychologically addicting. Long term of stimulants causes variying degree of intelactual, emotional, social and economic deteriotaion.

4. Narcotics- Like sedative narcotics produce a depressent effect on the centeral nervous system. They produce feeling of pleasure, strength and superiority, reduce fhunger and increase suggestability included in this catagogry are opium, heroin, morphine, cocaine, and cannabis. Heroin is a white powder made from morphine, cocine is made from leaves of coca-blush and known for its odourless.cannabis is obtained from the hemp plant. 5. Hallunicinogeus drugs- Produce distortious of perception and develop dream image. This drug use is not advised by medical practioners. The well known drug of this group is LSD.which is men made chemical. It is so powerful that one ounce produces three lakh human doses. LSD is taken orally but it may also be injected.

6. Nicotine in drugs- cigrattes, bidi, cigar, snuff and tobacco. Nicotin has no medical use. It leads to relexation, stimulates the central nervous system, increase wakefullness and remove bordom, but frequent use of necotine may cause heart attack,lung cancer and bronchitis, even the law does not classify this as a drug.

Control over drug abuse (Conclusion)

The control over drug abuse can be made possible by adopting the following measures:

Parents need to play a most cruicial role in the controlling drug abuse among their children. Since parental neglected, over hostility, rejecton, maritial disharmony play a important role inperputating drug addiction parent have to take more care in keeping the family envirinment conginal and harmonious. Since addiction does not develop overnight and it involves a proc ess of evoluation of losing interest in studies, activities, hobbies, indulging in irresponsible behaviour irritating impulsive conduct and having a dazed expression, parents can locate the early signs by being eleart and can make sure that the child withdraws from the habit. The role of parents could be communicate openly with the children, set an example for children by not taking drug or alcohol, keep track of prescribed drug in home, take interest in children's activities and their circle of friends, learn as much as about drugs, a change in the attitute of doctors in prescribing too many drugs can go a long way in controlling the abuse of drugs. The doctor hove to show a greater care in not ignoring the side effect of the drugs.

\section{REFERENCES}

[1]. Stark,rodney," Alcoholosim and drug addiction" in social problems, Random house, Toronto 1975

[2]. Nowlis,Helen H., Drug on the college campus, Anchor books, New york, 1969

[3]. McClelland,David, The drinking man, Free press, New York,1977

[4]. Hirshi, Travis, Causes of delinquency, University of California press, Barkeley, 1969

[5]. Chein, Isodore, Psychological functions of drug use, In stenberg(ed), Churchill illinious, 1970

[6]. Blachly,Paul, H, Drug abuse, Charles C.Thomas, illinious, 1970

[7]. Akers, Ronald.L, Deviant behaviour; A social learning approach, Belmont, Wadsworth,1973

[8]. Carey,Jarnes,L “The college drug sceane” Prentice-Hall, Englewood cliffs, 1968

[9]. Jullian,Joseph, Social problem, Printice-Hall, Englewood cliffs, 1968 